\title{
Unions and industrial improvement projects: Building a common momentum
}

\section{Lars Harald Lied}

\begin{abstract}
The purpose of this article is to define the potential role unions can play in a general quest for improved practice in an industrial company. Workplace innovation (WPI) is one example of such a measure. Lean is another. The article outlines important elements when implementing improvement tools like Workplace Innovation and Lean practice. The efforts are focused at company level, and experiences from a Norwegian industrial company highlight the areas of importance. The amplifying role a union can play in an improvement process is discussed, and motives and processes are clarified, in order to show the role of unions in a broader sense. The "Nordic" tradition of organising work-life frames the considerations made in this paper, but elements of experience can also be valuable in other work-life traditions. Practical improvement is the ultimate goal in an improvement project, and this article shows how unions can play an active part and amplify the results when it comes to enhancing organisational performance. Theories and experiences are supported by interviews with experienced leaders and employee representatives. Changes are often met with resistance, and the article shows that unions, under certain circumstances, can play a facilitative role when it comes to the implementation of improved practice. Joint motives provide a unique opportunity to succeed, and Workplace Innovation and other improvement measures can represent a "win - win" formula in that sense. A democratic and dialogical approach towards Work Life design contributes to both efficiency and stimulating workplaces through Workplace Innovation and Lean Management.
\end{abstract}

Keywords: Co-determination, Organisational performance, Improvement projects involving unions, Job satisfaction, Lean Management, Organisational Performance, Workplace Innovation 


\section{Introduction}

How can the union approve the implementation of Lean? Is Lean a rationalisation tool for downsizing when it demonstrates overcapacity? In some literature, Lean has been called an "ideological assault upon organised labour" ( Stewart et al. (2009, p. IX). It is easy to make arguments for "Mean Lean" representing an improvement tool violating the interest of the employees. Old Lean interpretation came as a tool based reaction to mass production and Fordism. The original "Toyota" way of Lean practice became somehow lost and redefined in the American interpretation (Shimokawa 2012). Today, businesses around the world practice Lean principles in a way adapted to culture and values. Lean still has a strong position when it comes to improvement of practice. The evolution of Lean has gone through stages, and this history can tell us both positive and negative stories. Unions have played a significant role in the industrial development around Lean, and this article will focus on the important role unions can play in improvements processes on a company level. How can a modern interpretation and implementation of Lean and other tools of improvement become stronger through social partnering? This article will introduce relevant theories, methodologies and examples followed by discussion and conclusion.

\section{Setting the stage}

The unions represent the employees, and their objectives will always be focused upon them. They will promote the interest of their members. The role that the unions have been playing throughout history has changed, and it is now in their interest to revitalise, by highlighting new areas within the Work Life arena. New measures and new objectives can assure them a strong and influential role in the future. The union(s) must make choices regarding their positioning within the corporate sphere. These choices include different social partners and dimensions. According to Huzzard, Gregory \& Scott (2004, p. 27) these choices are:

1. Choices on union missions historically are ideologically shaped and form the basic identity of the union organisation.

2. Choices are made on the scope of union activities and relationships

3. Decisions in terms of how they engage with civil society

A union must deal with members, employers, other unions and society within an economical framework (social partners). Interaction with social partners takes place at different levels (International, national, regional, local and company), and it takes place within a given political and cultural setting. How a union chooses to take a position depends on different conditions. They must set short and long term goals, and decide upon their mission. Historically unions emerged as the result of industrial growth and the traditional and conflict-ridden relationship between capital and labour. Huzzard, Gregory \& Scott (2004) use "boxing and dancing" as a metaphor in their book Strategic Unionism and Partnership. The adversarial approach is represented by boxing, and the co-operative approach describes the dancing

Figure 1 Boxing and dancing illustration 
(Huzzard, Gregory \& Scott 2004, p. 3). It is a state of war and peace. Metaphors linked to boxing and dancing are used throughout the book as symbols of actions taking place in Work Life. The unions have many different social partners and different areas of interest. The combination of these "pieces" opens up a pathway to new and constructive solutions. The cooperative strategy may differ between the areas, but it requires strictly defined roles and a steady hand. The fight takes place on both an international / national arena and on a more local / company level. The boxer's stance is vital to how one part takes the punch from an opponent. This positioning has developed over time, and we have gradually seen other solutions aiming

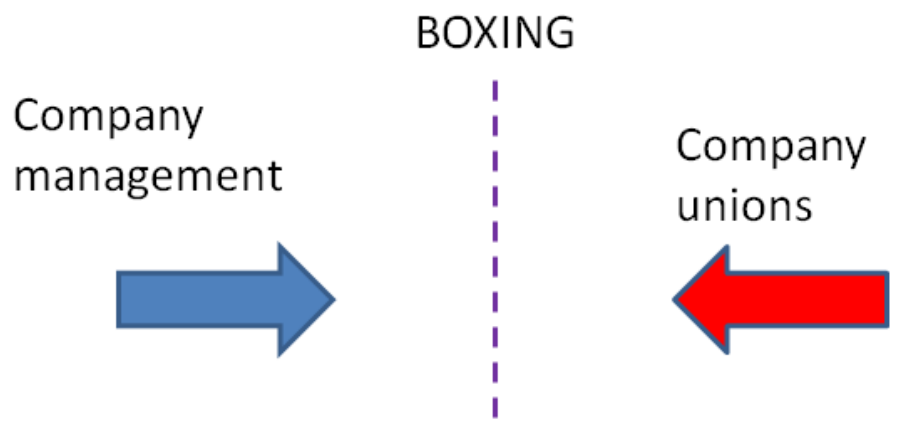

Figur 2 Boxing and dancing illustration

for common advantages and constructive co-operation. Moving from boxing to dancing requires a dance floor where all participants can participate on level footing. The mindset of the boxers must be changed towards progress through collaboration and partnership. Cooperative measures have proved to be effective, and the power distance has been reduced. In Norway, the introduction of the Employment Protection Act of 1977 can be interpreted as a milestone in the change of discourse in Work Life.

After developing as a part of industrial revolutions, unions have succeeded in securing their fundamental interests such as decent working conditions and wages. They feel that their contribution has been most important in the creation of today's prosperous society, and in that sense feel "ownership". This notion is also present at company level. Not in a juridical way, but employees feel ownership of the success that is objectified by their company. We (the unions) are "a part" of the company because our efforts have been vital ingredients for success.

New situations require new measures, and the unions of today are in a position where they can choose to develop other areas of interest if their fundamental requirements are satisfied. These new areas of focus emerge through maturity, and they must be seen as supplements to more traditional areas of interest. From a union perspective, WPI and Lean practice are definitely areas of interest. According to the $3^{\text {rd }}$ European Company Survey, Workplace Innovation (WPI) is:

A developed and implemented practice or combination of practices that structurally (through division of labour) and/or culturally (in terms of empowerment of staff) enable employees to participate in organisational change and renewal to improve the quality of working life and organisational performance (Oeij P 2015, p. 8). 
Such a definition calls upon the attention of a union. Unions want to influence how implementation of such measures is carried out, and also ensure that such actions are aligned with the interests of their members.

If we make it a starting point that the basic needs of a union (salary and well-being) are generally fulfilled, we face other work-life challenges to solve on our way to better practice. WPI and Lean represent (among others) tools of practice that can help us reach higher levels of performance, and they have many common denominators. They require support from top management and must be implemented in the whole of the organisation on terms agreed upon. Lean and WPI are not concepts you practice on Fridays only! There must be a broad and knowledge-based understanding on all organisational levels, on how to employ these practices. Implementation requires knowledge and engagement from both management and employees. Such knowledge should be based upon organisational experiences and culture, because the process of implementation is sensitive and elements of alienation will weaken the progress. It is important that implementation occurs gradually, so that understanding and acceptance among participants can emerge through a natural maturation process, as participants "buy in" to changes. All participants must be prepared ahead of implementation via an open dialogue discussing the reasoning behind the launch of the initiative.

The Nordic tradition of organising Work Life evolved into a democratic and involving model after the Second World War. Democracy, trust, respect and transparency are common features of the Nordic work-life design, and it is observed in practice through employee involvement and dialogue. This egalitarian design has developed a dance floor over time, and today the cooperative model is robustly embedded in the handling of all work-life issues. There has been a movement from negotiation to collaboration between social partners over the last 40 years.

Union participation in business development is a sensitive issue. Marked by the traditional capital vs. labor confrontation, there are historically strong voices arguing that the representation of workforce interest is undesirable. Union participation in strategic decisionmaking processes, not least in the United States, is rare (Appelbaum \& Hunter 2003). This reluctance goes both ways. (Appelbaum \& Hunter 2003) refer to Thomas Donahue, an AFLCIO Secretary- Treasurer, summarised the traditional viewpoint in a 1976 speech:

Because American unions have won equality at the bargaining table, we have not sought it in corporate boardrooms. We do not seek to be a partner in management to be, most likely, the junior partner in success and the senior partner in failure.

We do not want to blur in any way the distinctions between the respective roles of management and labor in the plant. We guard our independence fiercely independent of government, independent of any political party, and independent of management.

This article does not address the question of whether it is right or wrong to launch cooperative measures between management and union even though it argues for such cooperation. Arguments must reflect the situation they describe. This speech was held 1976. Situations change, and our arguments must change accordingly. 


\section{Description}

\section{A practical example of an improvement project}

In order to highlight the topic of this article, an example from Norwegian Work Life is used. The author of this article is an "insider" employed in the company used in the case study. In addition to 12 years' experience of employment, data was gathered during a Lean Management improvement project designed with the principles of action research. Such point of departure calls for special attention when it comes to validity, but all research must be valid in terms of process and documentation, and "The research must go through the natives" (Eikeland 2006, p. 209) .

This case study has some features that make it unique, but it shows a challenging process of change solved by common efforts. The Raufoss industrial park has 2500 employees distributed amongst 15 different industrial manufacturing companies. Industrial production goes back to the 1890's, and today the industrial activities are focused around defence products and light metal automotive products. Technology is a driving force, and highly skilled employees are found at every level of each organisation. Nammo Raufoss AS is a producer of defence related products, and the company has 760 employees. In a Norwegian context, this is a large company. There are approximately 400 blue collar workers, and they are all organised in the same union. The level of competence among the blue collar employees is high, and $70 \%$ are skilled workers with a formal professional education! Industrial work-life is traditionally anchored, and basically founded on the principles of the Norwegian model. The last 130 years of industrial history contain many examples of boxing between unions and employers, but the modern day focus is more concentrated on keeping jobs safe in an international, automated and complex world (dancing). According to the local union leader, today's employee - management partnership "would have been unthinkable only 20 years ago". This statement emphasises a fast moving and continuously changing work-life. Labour productivity and quality are high; and these features, in combination with a strong capacity for innovation, have generated a strong industrial position that has resulted in profitability for several decades. Both the unions and the company's management are focused on further development of the company, and this attitude characterises the co-operative work-life design of the company (dancing).

Nammo Raufoss AS is a part of an international corporation that is continuously working to improve its industrial performance (Nammo AS). The company has a long history of employing different improvement practices such as Agile, PDCA (continuous improvement) and Lean. Today, the parent company has chosen to consolidate their continuous improvement efforts in a Lean Six Sigma programme. Improvement work is strongly supported by internal courses in both Lean Six Sigma and Lean methodology in particular. These courses involve employees at every level. Engagement with employees at every level, combined with their high skill level, ensures broad involvement and a sense of ownership of the continuous improvement process among the employees. Lean methodology and practice have become a natural part of how work is organised, and it is strongly aligned with the corporate culture (Norwegian model). Unions 
have gradually become a natural part of the implementation of Lean, and today they take a shared leadership role in its implementation.

In order to gather data around the role of the unions in industrial improvement projects, a series of interviews highlighting the issue of union participation in improvement projects were conducted. One round of semi-structured interviews with top management, white collar union leaders and blue collar union leaders was completed. The company is in the middle of a company-wide implementation of a Lean Six Sigma improvement process, and the development of leadership practices in facilitating Lean practice is highlighted. Practical training of leaders and employee representatives is being conducted, and this background framed these interviews. The response obtained during these interviews indicates some interesting features with regard to social partnership as they exist in the Norwegian work-life model. The constraints must, naturally, be evaluated in each situation, but the experiences from Nammo Raufoss AS can also be generalised.

The management representatives emphasised the importance of including the employees in major industrial improvement projects. The CEO stated that "Employee representatives are also managers". He described them as managers with clearly defined assignments within their area of responsibility. The managers taking part in the interview also stated that an early involvement of employees provided a smoother implementation and it created a higher degree of motivation. They pointed out that the blue collar union, due to its size, experience and constitution was able to play an active role in improvement processes. The blue collar union at Nammo Raufoss AS is in a position to choose whether or not they want to play an active part. By taking part, they have the ability to influence how new measures and practice take shape. Through early involvement, this influence can affect every part of the improvement process. One of the production managers pointed to practical improvement in production supported by the blue collars union. The interview with the managers also showed that influence on improvement processes can facilitate through structures other than the union. Individuals and departments can influence processes in both positive and negative ways, and it is important not to "go blind" by only focusing a single structure. Social and communicative complexity requires a holistic approach and understanding when it comes to managing improvement processes. The role of the leader is vital, and s/he was described as a person who actively needs to push the process forward. Today's leader role was described by the managers as new due to the increased level of competence among production workers. Compared to the previous leader role marked by "steering and control", today's leader role was described as more facilitative, and focused on the utilisation of competence held by the employees. Future industrial success requires a highly competent work force.

The blue collar union leaders described their co-operation with management as very good. They clearly understood the potential for an active use of the union structure as an amplifier within improvement projects. Their collective strength is obvious, and it holds the potential to generate a positive momentum. The blue collar union leaders also pointed to relations between the leader and the employees as a key factor for success. According to them; "bad leadership leads to dissension due to fuzzy directions, but good leadership provides an inspirational attitude among 
the workers". Personality traits of the leader were identified as essential for success. Members of the blue collar union are divided when it comes to the implementation of new practices such as Lean. This fact does not mean that an implementation will end up in failure, but it underlines the importance of providing relevant information, training and involvement. Blue collar union leaders described their own role as important to how changes, like Lean, were comprehended by their members (gatekeepers). They described their own impact as considerable. Enthusiasm was described as being essential, not only by the union leaders, but also by the local employee representatives in every department. Engagement is contagious, and possible resistance will be reduced over time with the engagement of union leaders from the beginning of the process.

The white collar union leaders also described their relation to the management as very good. They felt closeness to the way the management of the company was conducted. Since they are represented in all formal structures of decision-making, they described their interests as being taken good care of. The white collar representatives could not identify their role in an improvement process in the same way as described by the blue collar representatives. They saw the potential for such co-operation, but they have no previous experience of playing this role. According to Huzzard, Gregory \& Scott (2004, p. 97) "the involvement of white-collar unions in workplace development projects is less common", and experience from this case study supports this statement. The main focus of these white collar unions have been on traditional union assignments like salary negotiation, educational measures and the well-being of their members. They have little experience beyond these traditional issues of union work.

The white collar unions in this case study do not have $100 \%$ membership among their potential members. There are several different unions to choose among, and many white collars choose not to unionise even though there is an established culture for it.

The white collar representatives emphasised the importance of early involvement in processes (voice of the employees). Involvement does not necessarily mean the use of the union structure, but there can also be other structures for co-operative measures. The representatives pointed at the involvement itself as the main issue. This involvement is the prime source for acceptance and motivation among employees. The white collar representatives were willing to take part in future improvement processes, but they made it clear that an initiation of such measures was a management responsibility.

\section{Discussion}

\section{0's UK automotive production: an example from another time}

In order to highlight the speed and breadth of the changes that have taken place, an example from the UK automotive industry is used. The automotive industry has been the cradle of industrial improvement work. The Toyota Production System (TPS) was the initial starting point of what we today refer to as Lean production. Lean practice emerged in the automotive industry due to the important principles of "flow" and "pull" in value adding processes (Liker 2004, p. 7). 
The situation in the British automotive industry in the last decade of the twentieth century is well described in the book "We sell our time no more" (Stewart et al. 2009). The authors describe an industrial situation marked by economic recession and downsizing. The European car industry was struggling with overcapacity, takeovers and restructuring of the business. The situation was difficult, and the question of closing down production at certain plants became a question. The book describes a situation where the management used Lean as a tool of how to re-organise the business sector in a way that could create profitability. The description of how Lean was practiced (purified) is quite brutal, since it often resulted in sick leave and ill health among the employees (Stewart et al. 2009, p. 130). The human needs of the workers were ignored in order to reach economic targets. The authors further describe management as poor "leaving a lot to be desired", and all these factors lead to a "poorly paid and poorly trained workforce" (Stewart et al. 2009, p. 81). From the union's point of view, Lean became a threat and a management power game. "Capacity adjustments" were the objective, and Lean became the medium. It represented the opposite of the values the unions wanted to promote, and they were left without the possibility to influence how Lean should be practiced. Management forced their "production regime" upon the employees in a vulnerable situation. "The Leaner the company became, the more organised labour "Embraced and changed", the more shop floor workers sensed a growing disempowerment” (Stewart et al. 2009, p. 37).

The Norwegian and the UK examples represent two totally different situations. Times of prosperity or adversity result in different scenarios. It is not the intention to make a judgement in either of the cases, but it clearly shows how processes of change call for a climate that involves the employees in a genuine way. We often respond with resistance when decisions are made above our heads, and when solutions are forced upon us. The argument made in this article is that improvement processes, including change, should be facilitated by the involvement of the union. Most companies will probably find themselves somewhere "between" the two examples given, but it is important to understand the potential embedded in the social partnership design. Even though it requires a framework of prerequisites, a cooperative design can potentially add a greater momentum to the improvement process.

\section{Workplace innovation}

WPI is a concept with two major goals embedded. One is to enhance organisational performance. This objective can be reached through changes in organisational structures and procedures, and this first objective is mainly a management issue. The second goal embedded in WPI is the well-being of the employees. By listening to the "voice of the employees", it is possible to accommodate practical and productive solutions on their terms. Motivation and innovation increases through empowerment, and the employees are able to influence how their workplace is organised. The latter argument strongly fits the goal of a union. The challenge for "a partnership approach lies in the need to produce outcomes that provide gains to satisfy both business and social needs" (Huzzard, Gregory \& Scott 2004, p. 76) . Listening to the voice of the employees and taking care of their well-being are also core issues in the Nordic model. The relationship to the concept or term of WPI as defined above is fairly weak in practical Norwegian Work Life. It does not mean that WPI is not practiced, but it is more about the 
Norwegian WPI practice being a foundational element of the "Norwegian model" and is not derived solely from "WPI" theory. Many principles that constitute the practice of WPI are also fundamental parts of the Norwegian (or Nordic) model. As a result of the pre-existing conditions extant within the Norwegian model, introducing "WPI as a "new" concept becomes unnatural. According to Oeij P (2015, p. 42) "each configurational combination of casual condition is an implicit strategy to become a WPI company". There is no "one size fits all" when it comes to the practice of WPI. The potential of involvement in work-life has emerged throughout practice over time, and it has been categorised in five favourable arguments by Levin et al. (2012, p. 102):

- The argument of productivity

- The argument of quality

- The argument of attractiveness

- The argument of innovation

- The argument of preparedness

All these arguments could be made in the boardroom by the management. There is also an argument that the involvement of the union as a permanent part of a corporate democracy promotes the principles of WPI. Levin et al. (2012, p. 212) argues that the equilibrium of power in practical work-life creates WPI in practice. Strong union involvement calls for joint responsibility on every level of the organisation, and it is governed by a clear division of responsibilities.

\section{Issues of importance to the union}

The most important issue for employee representatives when it comes to the implementation of WPI (or Lean) is to ensure "the voice of the employees" (Oeij P 2015, p. 53). This topic even outranks "Job and income security". This observation clearly shows the importance of democratic values embedded in union related work. The request to influence your own work has risen in parallel with a higher degree of knowledge and education regarding work-life, and "the voice of the employees" must be regarded as important from both employer and employees point of view. It is one way in which management can show their respect and appreciation of the knowledge held by their employees.

Educational measures have become more important to unions. They want their members to feel empowered, and the possibility to enhance personal competence is important in this regard. It offers an opportunity to satisfy an employee's inner motivation by empowering her/him to take on more complex and interesting jobs. High levels of competence also contribute to competitive advantage for the firm, and improved job security for the individual employee, as the firm has invested in development of intellectual capital. A formal and higher degree of competence also 
puts an employee in a position for better compensation. A union will try to formalise parts of work-life in order to structure them within a set of rules. When an issue is formalised in this way, it becomes a part of a structure open for negotiation.

Autonomy and freedom within motivational frames are also important to employees and their unions. This is the counterpart to the old "steering and control" regime commonly used in industrial settings previously (Taylorism). The rising claim for higher skills due to new technology and complex systems, has given us an industrial operator that holds specialised and vital skills in a defined area of experience. Highly educated and skilled workers are more likely to produce better than average (Black \& Lynch 2004), and this benefits all social partners. Investing in a highly educated and skilled work-force can also lead to a more flexible workforce. It becomes easier to move employees around the organisation in response to the actual needs of the firm. This flexibility stands in contrast to rigid and fixed organisational structures, and it produces the freedom to adapt to varying needs. Such potential strengthens competitiveness in hard and changing times, and the unions have become more receptive to this need over time. Their ultimate goal is to secure safe and productive jobs that provide competitiveness for a firm and its employees in the long run.

The union has a choice when it comes to organisational processes. Do they want to dance (Huzzard, Gregory \& Scott 2004, p. 14)? They can actively take part in it, or they can choose not to. Norway has a long history leading up to the egalitarian work-life model practiced today. Power is shared equally between work-life participants within different areas of responsibility. Within this framework, it is natural for the union to engage in areas of interest beyond worktime and wages, and they have become an important partner when it comes to the implementation of improvement processes in a company.

\section{Management objectives}

Management is hired to generate profits for owners. Seen in isolation, this statement assumes a top down perspective on how the company functions as an organisation, but hard competition and experience has given us a situation where we need to utilise other perspectives towards organisational behaviour. WPI includes job tasks and organisational redesign. It may also include management redesign, in terms of more deliberate and goal-oriented use of the potential represented by the unions. Such considerations should become an integral part of how management sets their strategic objectives, and approaches employees to reach them.

Management practice and the organisational design of a company must support such cooperative improvement efforts. Project design, including the union must be based on values of mutual respect and involvement. Mutual respect and involvement are vital when it comes to how a company succeeds in social partnerships. The value of unions in formulating strategy and achieving corporate objectives is often underestimated by management (Stewart et al. 2009, p. 131), and such miscalculations work against the possibility of defining objectives of common interest. Management and union objectives are not always the same, but it is a common 
responsibility to define and develop potential areas of co-operative development. Organisational flexibility and high competence as mentioned previously both represent such areas.

Management objectives are often built up around key performance indicators (KPI's). Often, they are connected to economic values in a measurable way. If all organisational objectives are based on economic targets, a firm can miss the important dimension of human needs. In order to take care of human needs, the model should be revolved. Economic value creation should be the product of a work-life where the well-being of employees is integrated. Job re-engineering, when incorporated in Lean and WPI implementation, "is not a one-way process with a single outcome for employees well-being" (Anderson-Connolly et al. 2002, p. 390). It is a process creating multi-dimensional effects, some favourable and some unfavourable for workers. Management has a responsibility to ensure that change processes do not interfere with the wellbeing of the employees.

\section{Change and resistance}

Employees tend to meet changes in work-life with scepticism and resistance. Such a response is natural, since individuals and groups immediately start to ask themselves questions. What does this change mean to me? Is it a threat to me or my position? What is in this for me? Previous research shows that union membership is negatively related to the implementation of Lean when it comes to commitment (Angelis et al. 2011). This indicates that the union interprets the principles of Lean as running counter to their own agenda. Lean has by nature an intensifying effect on work since natural breaks are eliminated (waste), and this fact may provoke blue collar workers (Skorstod 1994, p. 449). Enhanced Lean commitment is conditional, and related to the effectiveness of management design and the practice of technological and human resource policies (Angelis et al. 2011). Managing change processes requires more than just leadership or management skills. In order to succeed with managing processes of change, you need to have knowledge of the elements important to the defined process. Leading change through competence is the only answer, according to Kotter (1996, p. IX). A union can play a facilitative role in the demanding process of implementing change. By participating in every part of a project they will not only act as a catalyst to the process, but they will also have the opportunity to influence matters of importance to the union. The "voice of the employees" is heard through union representation, and it secures commitment instead of resistance to the practical changes.

\section{Where are the borders between failure and success? Preconditions for success}

The model of amplifying an improvement process with strong and decisive union involvement needs some distinctive prerequisites. These preconditions are not fixed or absolute, but vary due to the corporate context. In order to succeed, the union must be well organised and also play a strong part in the culture of the company. Long and predictable relations of collaboration between union and management contribute to a productive process. The dance floor is cleared. The cultural heritage surrounding the process will act as a framework, and previous success will make a good starting point. The maturity of both the union and the management is 
important for success. Both parties need skilled leadership who understands the potential gains offered by co-operative solutions. "Inadequate skills at dialogue, on either side, can undermine the effectiveness of partnership (Huzzard, Gregory \& Scott 2004, p. 241). Embedded in this experience and maturity is a realisation that boxing between union and management results in energy draining confrontation. By choosing collaboration, both sides assume responsibility and make something better together.

As mentioned earlier, social partnership takes place on different levels and dimensions. In order to generate added value and progress for all partners, choices must be made. Social partners do not need to have a single strategy for interaction with other social partners. They can choose to adapt their approach and actions to the different arenas in which they participate. Such a multidimensional approach opens up possibilities for a combination of structures to produce added value. As an example, the unions can choose a historical approach to the core activities of negotiations regarding wages and working hours (boxing). They can enhance their boxing skills in this specific area and at the same time dance with social partners in other arenas. There is connection between boxing and dancing. According to Huzzard, Gregory \& Scott (2004, p. 247) "it would be foolish to think that disconnecting boxing from dancing will make the dance more successful". When it comes to the questions of taking part in improvement processes like WPI and Lean, the union can choose to actively take part and affect the decisions in the process. Their participation will also amplify the degree of success of the process (dancing). This divided and selective strategy requires adherence to strict roles and firm leadership. The social partners involved must agree on defining an area for dancing that promotes added value for all parties. On a company level it could be illustrated as shown in the figure below:

All parties must "give and take" in the process of building something larger. Joint efforts generate a higher output on the defined area. The "boxers" decide the size and the content of the "ring” (Huzzard, Gregory \& Scott 2004, p. 95).

The size of the company may be of some importance when considering joint improvement

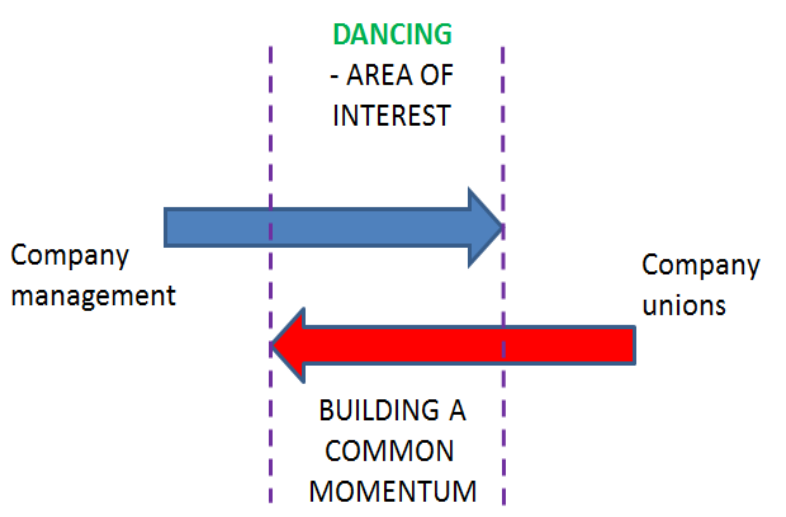

project design. Smaller companies may experience that the role of the unions are somewhat vague, and it then becomes difficult to objectify their role as a potential partner in a project. One or few strong unions are important to make this union - management collaboration strong. When the union is strong, they represent a clear and distinctive partner in a potential cooperation. They also represent "the voice of the employees", which is a strong argument. The 
strength of a union is measured by the numbers and share of members, network connections, experience and the organisational structure and capabilities they hold. An opposite situation with numerous unions makes it harder for management to arrange for joint project design. In the case study from Nammo Raufoss AS, the blue collar union represents $100 \%$ of the 400 potential members, and they are easy to identify as a potential partner when designing an improvement activity. They also represent a large body of institutional knowledge experience that makes them a potentially attractive partner.

Previous positive experience of social partnership between management and unions facilitates a potential joint project design. You "learn to dance" when working together, and co-operation around a common objective creates more trust that is useful for further steps. It must be emphasised that union - management collaboration puts the union representatives in a difficult position. They must cope with both satisfying their members (mandate) together with the cooperative role they play towards the management. This is a demanding position leaving them "between a rock and a hard place", but a distinctive division of roles and objectives may ease this pressure. "Dancing too closely with management can compromise the union's support from its members (Huzzard, Gregory \& Scott 2004, p. 78). You need to do two different things simultaneously, and it takes time to master this duality. Clarity and strict lines of responsibility help the employee representatives not to forget the interests of their constituents when working closely with company management.

\section{Conclusion}

There is a potential "win-win" for both management and unions in finding co-operative solutions when implementing improvement projects on a company level. Picture the company as an automotive engine, and the union can be seen to represent the "turbo charger" in a process of change. The process design must not create winners and losers, and all social partners must be involved on equal terms. Tasks and responsibilities are shared between stakeholders, and participants are motivated by taking part and contributing to something defined as common value. Transparency and openness are mandatory. When the prerequisites mentioned here are in place, improvement processes like WPI and Lean implementation are more likely to produce a positive result. Success in improvement yields improved competitiveness in an industrial setting.

WPI is more than a "Nordic obsession" (Totterdill, Cressey \& Exton 2012), and the union can make a difference in such improvement targeted processes. WPI is, to a great extent, improvement work on terms favourable to the union. It is of utmost importance to steer the potential energy that the union represents in the same direction as the improvement project itself. This is possible when the union is invited to participate in all stages of an improvement project.

Relations between unions and management are historically marked by power struggles (boxing). The unions have gained influence through the use of power, and today we see work- 
life structures that are more balanced. We have all experienced situations where one party wins at the cost of the other. From a WPI perspective, the co-operative approach in improvement projects represents an area with latent added value. WPI or Lean cannot be implemented partially in an organisation. Such a project represents an opportunity to unite around something that brings the company further along the continuum of improvement.

Collaboration on terms like this does not mean that the union and management need to agree on every issue. They are not "married", and genuine involvement and practical use of the union in this manner does not mean a "union takeover" when it comes to management of the company. Different subjects must be managed separately, with tasks and responsibly shared accordingly. Equally shared power also requires a division of responsibility. Experience from previous processes clearly shows that conflicts often lead to energy draining situations with sub-optimal results. "Experience" is the key word, because a dogmatic attitude towards traditional management and union roles and responsibilities seldom benefits the objectives sought by the planned improvement process. By finding common solutions, it is possible to enhance the output of the process compared with a solution based on negotiation only.

This article argues that the management of a company could, in a more defined and conscious way, leverage the potential energy of the union in improvements processes. Actually, it is not only up to management. An invitation to dance can also be initiated by the union(s). Conducted correctly, there is a potential for improved outcomes in every part of the process, and the democratic principles are safeguarded since the "voice of the employees" is heard throughout the union representation. By involving the union early in the planning of an improvement project, management gains a partner instead of an opponent. Naturally, one can present both pros and cons regarding such an approach, but it is at least an option worth considering when working with industrial improvement processes.

You reap what you sow.......

The examples given here with the automotive unions in 1990's UK and the blue collar union at Nammo Raufoss AS today are, of course, two totally different scenarios. Time and setting is fundamentally different. Our perspective on Lean has changed much over the last 25 years, and done the right way in collaboration with the unions, it will greatly benefit all social partners. Modern interpretation of Lean is not theoretical. It is more practical, compounded and holistic compared to the original TPS. A union can support implementation of Lean when they are genuinely invited into the process.

This article was not intended as an assessment of the union's role in those mentioned scenarios, but rather to demonstrate that co-operative and productive solutions benefitting both parties can be achieved. Right co-operative measures between management and union creates added value. Some may find this co-operative design provocative, but the potential benefits of social partnership cannot be ignored on our way to optimal work-life practice. Some of the 
characteristics that influence an improvement process have been high-lighted in this article, but it is important to emphasise that a co-operative design between social partners is not totally dependent on a positive economic framework. It is most likely easier to arrange such cooperative partnerships within a strong financial position, but the invitation to dance should also be considered when operating under economic strain. Added value lies in the combination of opportunities, and these opportunities appear in different dimensions. Today's Work Life offers much more than a traditional Marxist "employee vs. capital" approaches. Arrange for a knock out by learning to dance!

\section{About the author:}

Industrial $\mathrm{PhD}$ candidate employed by Nammo Raufoss AS, related academically to the University of Agder, Norway. Email lars.harald.lied@gmail.com

\section{References}

Anderson-Connolly R..et al. (2002) "Is lean mean? Workplace transformation and employee well-being". In: Work, employment and society, 16(3), p. 389-413.

Angelis J.et al. (2011) Building a high-commitment lean culture. In: Journal of Manufacturing Technology Management, 22(5), p. 569-586.

Appelbaum E. \& Hunter L.W. (2003) Union participation in strategic decisions of corporations: National Bureau of Economic Research.

Black, S. E.\& Lynch L.M. (2004) "What's driving the new economy?: the benefits of workplace innovation." In: The Economic Journal, 114(493).

Eikeland O. (2006) "'"The validity of Action Research. In: Action Research Journal.

Huzzard T., Gregory D. \& Scott R.. (2004) Strategic unionism and partnership: Boxing or dancing? Book of Abstracts. 135 p.

Kotte, J. P. (1996) Leading change: Harvard Business Press.

Levin M.et al. (2012) Demokrati i arbeidslivet. Den norske samarbeidsmodellen som konkurransefortrinn: Bergen: Fagbokforlaget.

Liker J. K. (2004) The Toyota Way: Esensi.

Oeij P., Dhondt S., Corral A., Totterdill P., Preenen P. (2015) Workplace innovation in European companies Publications Office of the European Union, Luxembourg: Eurofound.

Shimokawa K. (2012) The Birth of Lean: Lean Enterprise Institute.

Skorstod E. (1994). "Lean Production, Conditions of Work and Worker Commitment." In: Economic and industrial democracy, 15 p. 429. 
Stewart P.et al. (2009) We sell our time no more: Workers' struggles against lean production in the British car industry: Pluto Press.

Totterdill P., Cressey P. \& Exton R. (2012) "Social innovation at work: workplace innovation as a social process". In: Challenge Social Innovation: Springer, p. 241-259. 